\title{
Crystal Structure of One-dimensional $\left[\mathrm{ZnCl}_{2}\left(\mathbf{N}_{2} \mathbf{C}_{13} \mathbf{H}_{14}\right)\right]_{n}$ $\left(\mathrm{N}_{2} \mathrm{C}_{13} \mathrm{H}_{14}=1,3\right.$-bis(4-pyridyl)propane)
}

\author{
Sung Jin Hong, * Han KwaK,* Young Min LeE,* Cheal KIM,*† \\ Youngmee KIM, ${ }^{* * \dagger}$ and Sung-Jin KIM** \\ *Department of Fine Chemistry, Seoul National University of Technology, Seoul 139-743, Korea \\ **Division of Nano Sciences, Ewha Womans University, Seoul 120-750, Korea
}

\begin{abstract}
The ligand $\left(\mathrm{N}_{2} \mathrm{C}_{13} \mathrm{H}_{14}\right)$ bridges $\mathrm{Zn}(\mathrm{II})$ atoms to form a one-dimensional chain compound, and two chloro ligands are also coordinated to $\mathrm{Zn}(\mathrm{II})$ atoms. The coordination geometry of the $\mathrm{Zn}$ atom is distorted tetrahedral with a $\mathrm{Cl}-\mathrm{Zn}-\mathrm{Cl}$ angle of $125.69(3)^{\circ}$. The crystal packing is consolidated by both intra- and inter-chain $\mathrm{C}-\mathrm{H} \cdots \mathrm{Cl}$ interactions.
\end{abstract}

(Received August 5, 2005; Accepted October 12, 2005; Published on web December 28, 2005)

The crystal engineering of networked coordination polymers is of great current interest due to their potential properties for ion exchange, gas storage, molecular sensing, and catalysis. ${ }^{1,2}$ Many efforts have been devoted to investigating new synthetic strategies using novel rigid or flexible spacer ligands. ${ }^{3,4}$ In our previous attempt to investigate the design and control of the

Table 1 Crystal data and experimental data

Formula: $\mathrm{C}_{13} \mathrm{H}_{14} \mathrm{Cl}_{2} \mathrm{~N}_{2} \mathrm{Zn}$
Formula weight: 334.53
Temperature: $273(2) \mathrm{K}$
Crystal size: $0.25 \times 0.20 \times 0.10 \mathrm{~mm}^{3}$
Crystal color: colorless
Crystal description: block
Crystal system: Monoclinic
Space group: $P 2_{1} / m \quad Z=2$
$a=5.2254(4) \AA$
$b=12.9296(10) \AA$
$c=10.5169(8) \AA$
$\beta=94.1890(10)^{\circ}$
$V=708.65(9) \AA^{3}$
Calculated density: $1.568 \mathrm{Mg} / \mathrm{m}^{3}$
Radiation: $0.71073 \AA$ (Mo $\left.K_{\alpha}\right)$
$2 \theta_{\text {max: }}$ 56.26
$R=0.0314[1725$ reflections, $I>2 \sigma(I)]$
$w R=0.0854$
Goodness-of-fit $=1.149$
$(\Delta / \sigma)_{\text {max }}$ final cycle $=0.001$
$(\Delta \rho)_{\text {min, max }}=-0.459,0.598$ e $\AA^{-3}$
No. of reflections collected $=7732$
No. of reflections used $=1572$
No. of parameters $=88$
Diffractometer: Bruker SMART
Monochromator: graphite
Structure determination: Bruker SHELXTL
Refinement: full-matrix least-squares on $F^{2}$
Structural information was deposited at the Cambridge
Crystallographic Data Center $(\mathrm{CCDC} 285350)$.

To whom correspondence should be addressed.

E-mail: chealkim@snut.ac.kr; ymeekim@ewha.ac.kr self-assembly of coordination polymers with flexible bridging ligands, we synthesized different dimensional structures from different zinc salts with the flexible ligand 1,3-bis(4pyridyl)propane. ${ }^{5}$ In this study, we employed zinc chloride to continuously examine the counter-anion effect in combination with the same ligand. We report here on the crystal structure of a coordination polymer, $\left[\mathrm{ZnCl}_{2}\left(\mathrm{~N}_{2} \mathrm{C}_{13} \mathrm{H}_{14}\right)\right]_{n}\left(\mathrm{~N}_{2} \mathrm{C}_{13} \mathrm{H}_{14}=1,3-\right.$ bis(4-pyridyl)propane).

All chemicals used were of analytical reagent grade, and were used directly without further purification. Colorless crystals were obtained from a direct diffusion technique in which an aqueous solution of $\mathrm{ZnCl}_{2}$ was carefully layered by a methanol solution of $\mathrm{N}_{2} \mathrm{C}_{13} \mathrm{H}_{14}$. The X-ray diffraction data for the title compound were collected on a Bruker SMART AXS diffractometer equipped with a monochromator in the Mo $K_{\alpha}(\lambda$ $=0.71073 \AA$ ) incident beam. A colorless crystal was mounted on a glass fiber. The crystal and experimental data are given in Table 1. The CCD data were integrated and scaled by using the Bruker-SAINT software package, and the structure was solved by the direct method and refined by using SHEXTL V6.14. The atomic coordinates for non-hydrogen atoms are listed in Table 2 , and the selected bond distances and angles are listed in Table 3. All hydrogen atoms were placed at the calculated positions.

Table 2 Atomic coordinates $\left(\times 10^{4}\right)$ and equivalent isotropic displacement parameters $\left(\AA^{2} \times 10^{3}\right)$. $U(\mathrm{eq})$ is defined as one third of the trace of the orthogonalized $U_{i j}$ tensor

\begin{tabular}{lrlll}
\hline & $x$ & $y$ & $z$ & $U(\mathrm{eq})$ \\
\hline $\mathrm{Zn}(1)$ & $4588(1)$ & 7500 & $7208(1)$ & $46(1)$ \\
$\mathrm{Cl}(2)$ & $7498(1)$ & 7500 & $8883(1)$ & $53(1)$ \\
$\mathrm{Cl}(1)$ & $5459(1)$ & 7500 & $5160(1)$ & $62(1)$ \\
$\mathrm{N}(1)$ & $2456(2)$ & $6188(1)$ & $7411(1)$ & $44(1)$ \\
$\mathrm{C}(1)$ & $529(3)$ & $5936(1)$ & $6560(2)$ & $52(1)$ \\
$\mathrm{C}(2)$ & $-1027(4)$ & $5086(1)$ & $6693(2)$ & $52(1)$ \\
$\mathrm{C}(3)$ & $-570(3)$ & $4435(1)$ & $7737(2)$ & $45(1)$ \\
$\mathrm{C}(4)$ & $1441(4)$ & $4700(1)$ & $8608(2)$ & $52(1)$ \\
$\mathrm{C}(5)$ & $2879(3)$ & $5569(1)$ & $8424(2)$ & $50(1)$ \\
$\mathrm{C}(6)$ & $-2125(3)$ & $3477(1)$ & $7920(2)$ & $51(1)$ \\
$\mathrm{C}(7)$ & $-625(4)$ & 2500 & $7644(2)$ & $46(1)$ \\
\hline
\end{tabular}


Table 3 Selected bond lengths $[\AA]$ and angles $\left[{ }^{\circ}\right]$

\begin{tabular}{llll}
\hline $\mathrm{Zn}(1)-\mathrm{N}(1)$ & $2.0485(13)$ & $\mathrm{Zn}(1)-\mathrm{Cl}(1)$ & $2.2334(6)$ \\
$\mathrm{Zn}(1)-\mathrm{Cl}(2)$ & $2.2412(6)$ & & \\
& & & \\
$\mathrm{N}(1)-\mathrm{Zn}(1)-\mathrm{N}(1) \# 1$ & $111.75(7)$ & $\mathrm{N}(1)-\mathrm{Zn}(1)-\mathrm{Cl}(1)$ & $104.54(4)$ \\
$\mathrm{N}(1)-\mathrm{Zn}(1)-\mathrm{Cl}(2)$ & $105.13(4)$ & $\mathrm{Cl}(1)-\mathrm{Zn}(1)-\mathrm{Cl}(2)$ & $125.69(3)$ \\
\hline
\end{tabular}

Symmetry transformations used to generate equivalent atoms: $\# 1:-x,-y+3 / 2, z, \# 2: x,-y+1 / 2, z$

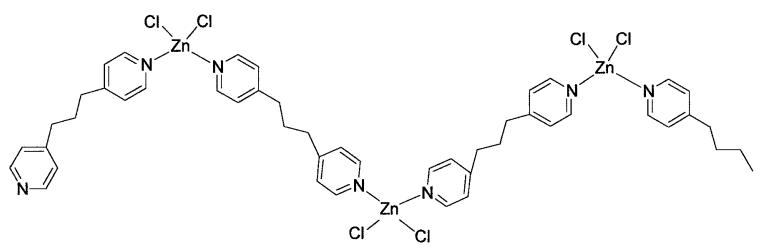

Fig. 1 Structural chemical diagram.

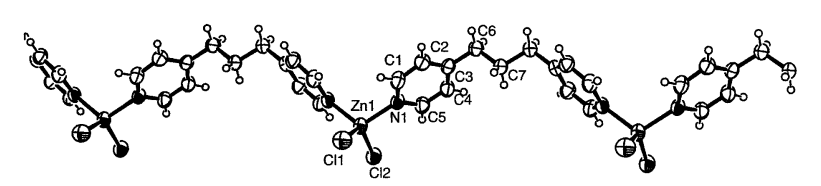

Fig. 2 Structure of one-dimensional chain, $\left[\mathrm{ZnCl}_{2}\left(\mathrm{~N}_{2} \mathrm{C}_{13} \mathrm{H}_{14}\right)\right]$ along with the labeling atoms.

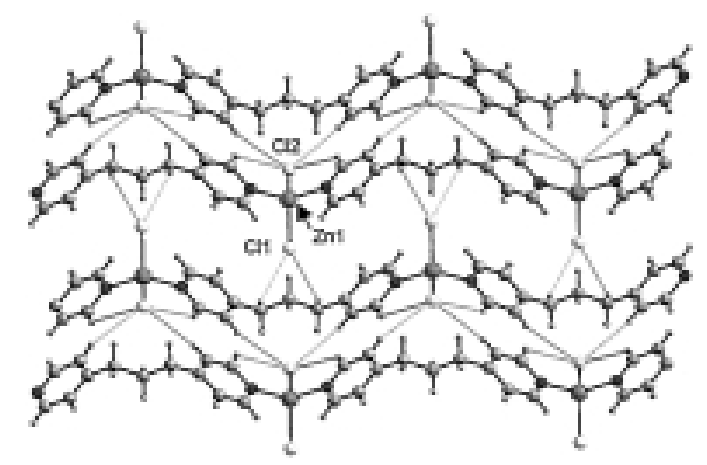

Fig. 3 Crystal structure including intra- and intermoleculal noncovalent interactions.
The molecular structure was drawn by Ortep- 3 for the Windows program. A chemical diagram is shown in Fig. 1, and the structure is shown in Fig. 2.

The ligand $\left(\mathrm{N}_{2} \mathrm{C}_{13} \mathrm{H}_{14}\right)$ bridges $\mathrm{Zn}(\mathrm{II})$ atoms to form a onedimensional chain compound, and two chloro ligands are also coordinated to $\mathrm{Zn}$ (II) atoms (Fig. 2). The asymmetric unit of the title compound contains half of the formula $\left(\mathrm{Zn}\left(\mathrm{N}_{2} \mathrm{C}_{13} \mathrm{H}_{14}\right) \mathrm{Cl}_{2}\right)$. The whole chain is generated by two crystallographic mirror planes: one resides through $\mathrm{Cl1}-\mathrm{Zn} 1-\mathrm{Cl} 2$, and the other through H7A-C7-H7B. The Zn-N distaance is $2.0485(13) \AA$, and the $\mathrm{Zn}-\mathrm{Cl}$ distances are 2.2334(6) and 2.2412(6) $\AA$ which are typical for $\mathrm{Zn}$ complexes. The $\mathrm{Zn}$ atom is coordinated by two nitrogen atoms from the ligands and two chloro ligands, and the coordination geometry of the $\mathrm{Zn}$ atom is distorted tetrahedral with $\mathrm{N}-\mathrm{Zn}-\mathrm{N}$ and $\mathrm{Cl}-\mathrm{Zn}-\mathrm{Cl}$ angles of $111.75(7)^{\circ}$ and $125.69(3)^{\circ}$, respectively (Table 3). Crystal packing in the title compound is consolidated by both intra- and inter-chain $\mathrm{C}-\mathrm{H} \cdots \mathrm{Cl}$ non-covalent interactions ${ }^{6}$ (Fig. 3). The intra-chain interaction is between $\mathrm{C} 5-\mathrm{H} 5$ and $\mathrm{Cl} 2$ with a distance of $2.87(1) \AA$, and the inter-chain interactions are between $\mathrm{C} 4-\mathrm{H} 4$ and $\mathrm{Cl} 2$ of the neighbor chain $(2.989(1) \AA)$ and between C6-H6A and Cl1 of the neighbor chain (3.031(1) $\AA$ ).

\section{Acknowledgements}

Financial support from the Korean Science \& Engineering Foundation (ABRL R14-2003-014-01-001-0) and Korea Research Foundation (2002-070-C00053) is gratefully acknowledged.

\section{References}

1. S. A. Barnett and N. R. Champness, Coord. Chem. Rev., 2003, 246, 145.

2. S. J. Hong, J. Y. Ryu, J. Y. Lee, C. Kim, S. -J. Kim, and Y. Kim, Dalton Trans., 2004, 2697.

3. B. D. Wager, G. J. McManus, B. Moulton, and M. J. Zaworotko, Chem. Commun., 2002, 2176.

4. A. J. Blake, N. R. Champness, S. S. M. Chung, W. -S. Li, and M. Schröder, Chem. Commun., 1997, 1005.

5. J. Y. Lee, S. J. Hong, C. Kim, S. -J. Kim and Y. Kim, Inorg. Chem. Commun., 2005, 8, 692.

6. C. Janaik and T. G. Scharmann, Polyhedron, 2003, 22, 1123 . 